\title{
Adaptive feedforward control of exhaust recirculation in large diesel engines
}

Nielsen, Kræn Vodder; Blanke, Mogens; Eriksson, Lars; Vejlgaard-Laursen, Morten

Published in:

Control Engineering Practice

Link to article, DOI:

10.1016/j.conengprac.2017.05.003

Publication date:

2017

Document Version

Peer reviewed version

Link back to DTU Orbit

Citation (APA):

Nielsen, K. V., Blanke, M., Eriksson, L., \& Vejlgaard-Laursen, M. (2017). Adaptive feedforward control of exhaust recirculation in large diesel engines. Control Engineering Practice, 65, 26-35.

https://doi.org/10.1016/j.conengprac.2017.05.003

\section{General rights}

Copyright and moral rights for the publications made accessible in the public portal are retained by the authors and/or other copyright owners and it is a condition of accessing publications that users recognise and abide by the legal requirements associated with these rights.

- Users may download and print one copy of any publication from the public portal for the purpose of private study or research.

- You may not further distribute the material or use it for any profit-making activity or commercial gain

- You may freely distribute the URL identifying the publication in the public portal

If you believe that this document breaches copyright please contact us providing details, and we will remove access to the work immediately and investigate your claim 


\title{
Adaptive Feedforward Control of Exhaust Recirculation in Large Diesel Engines
}

\author{
Kræn Vodder Nielsen ${ }^{\mathrm{b}, \mathrm{a}}$, Mogens Blanke ${ }^{\mathrm{b}, \mathrm{c}}$, Lars Eriksson ${ }^{\mathrm{d}}$, Morten Vejlgaard-Laursen ${ }^{\mathrm{a}}$ \\ ${ }^{a}$ MAN Diesel 83 Turbo, Teglholmsgade 41, Copenhagen, Denmark \\ ${ }^{b}$ Automation and Control Group, Dept. of Electrical Engineering, Technical University of Denmark, Kgs. Lyngby, Denmark \\ ${ }^{c}$ AMOS CoE, Institute of Technical Cybernetics, Norwegian University of Science and Technology, Trondheim, Norway \\ ${ }^{d}$ Vehicular Systems, Department of Electrical Engineering, Linköping University, Linköping, Sweden
}

\begin{abstract}
Environmental concern has led the International Maritime Organization to restrict $\mathrm{NO}_{x}$ emissions from marine diesel engines. Exhaust gas recirculation (EGR) systems have been introduced in order to comply to the new standards. Traditional fixed-gain feedback methods are not able to control the EGR system adequately in engine loading transients so alternative methods are needed. This paper presents the design, convergence proofs and experimental validation of an adaptive feedforward controller that significantly improves the performance in loading transients. First the control concept is generalized to a class of first order Hammerstein systems with sensor delay and exponentially converging bounds of the control error are proven analytically. It is then shown how to apply the method to the EGR system of a two-stroke crosshead diesel engine. The controller is validated by closed loop simulation with a mean-value engine model, on an engine test bed and on a vessel operating at sea. A significant reduction of smoke formation during loading transients is observed both visually and with an opacity sensor.
\end{abstract}

Keywords: Exhaust gas recirculation, EGR, diesel engines, feedforward control, adaptive control.

\section{Introduction}

Emissions of $\mathrm{CO}_{2}, \mathrm{SO}_{x}$ and $\mathrm{NO}_{x}$ have in recent years received an ever growing attention due to their environmental effects. The International Maritime Organization (IMO) has introduced a stepwise restriction to $\mathrm{NO}_{x}$ emissions from marine diesel engines, so far culminating in the Tier III standard (International Maritime Organization, 2013). For large two-stroke diesel engines this standard dictates a reduction by a factor of four compared to the Tier II standard and applies to vessels built after 1st of January 2016 when operating in specified $\mathrm{NO}_{x}$ Emission Control Areas (NECAs). As for now the North American coastal area is a NECA but serious steps have been taken toward including the North Sea and Baltic Sea as NECAs as well (HELCOM, 2016). The substantial reduction specified in the Tier III standard requires significant changes to the modern marine diesel engines and a number of solutions are being investigated and developed into products. The most common methods are to either remove $\mathrm{NO}_{x}$ from the exhaust with a selective catalytic reduction system or avoiding formation of $\mathrm{NO}_{x}$ in the first place either by implementing an exhaust gas recirculation system or by using a gas- or dual-fueled engine. This paper focuses on control of high-pressure Exhaust Gas Recirculation (EGR) for large two-stroke diesel engines.

Email addresses: krvni@elektro.dtu.dk (Kræn Vodder Nielsen), mb@elektro.dtu.dk (Mogens Blanke), larer@isy.liu.se (Lars Eriksson)
The main source of $\mathrm{NO}_{x}$ emission from a large twostroke diesel engine is thermal $\mathrm{NO}_{x}$ which is formed during the combustion process, where excessively high peak temperatures lead to reactions between nitrogen and oxygen. These reactions are known as the Zeldovich mechanism (Heywood, 1988). Recirculation of exhaust gas to the combustion process increases heat capacity and decreases the availability of oxygen, resulting in lower peak temperatures during combustion and thus decreased formation of $\mathrm{NO}_{x}$. A simplified overview of the airflow of a large twostroke engine with high-pressure EGR developed by MAN Diesel \& Turbo is shown in Figure 1. In the EGR string (on the left) exhaust gas is cleaned and cooled in the EGR Unit, pressurized by the EGR blower and mixed into the scavenge flow.

The amount of air that is to be recirculated in the EGR string is implicitly decided by calculation of a number of operating points in which the $\mathrm{NO}_{x}$ emission is within the legislated limits. These points are characterized by engine load and molar scavenge receiver oxygen fraction $\left(O_{s r}\right)$ as seen in Figure 2. The goal of the EGR controller is then to reach this $O_{s r}$ setpoint given the engine load condition.

The reference EGR controller applies fixed gain proportional-integral feedback control. In steady engine load scenarios the $O_{s r}$ setpoint is kept within desired bounds but whenever the engine load (and thus the fuel flow) changes, the EGR controller is in trouble. The slow nature of the system and a significant delay in the measurement of $O_{s r}$ limit the possible disturbance rejection of the feedback 


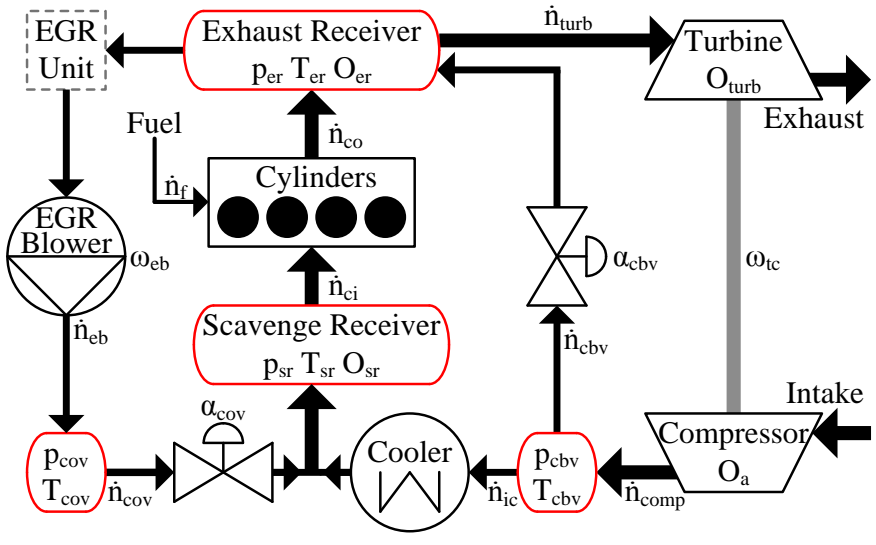

Figure 1: Overview of main gas flows and components of the engine with exhaust gas recirculation and cylinder by-pass valve.

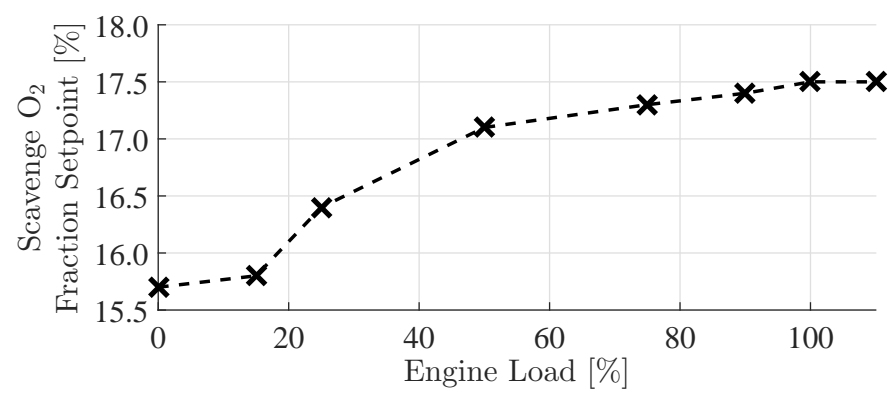

Figure 2: An example of required scavenge oxygen fraction as a function of engine load. The linearly interpolated commissioning points are specific to the engine.

control. In fast loading transients an increase in fuel injection decreases the oxygen fraction in the recirculated gas and thus less gas should be recirculated to keep the oxygen fraction in the scavenge mix at its setpoint. The delayed measurement and late reaction of the EGR controller can result in severe negative peaks in $O_{s r}$ leading to formation of black exhaust smoke for more than 45 seconds. With the PI EGR controller it is necessary to restrict the engine loading rate in order to avoid this smoke. However, such a solution is not viable as the NECAs mainly cover ports and coastal areas where maneuvering capability is essential.

\subsection{Literature}

Extensive treatment of combustion engine processes and modeling can be found in works such as (Heywood, 1988; Guzzella and Onder, 2010; Eriksson and Nielsen, 2014). Relevant treatment of large two-stroke crosshead engines mainly include governor design (engine speed control) as found in (Blanke, 1986; Blanke and Nielsen, 1990; Winterbone and Jai-In, 1991; Banning et al., 1997; Xiros, 2002). This led to investigation and development of dynamical models of engine speed response, where turbocharger dynamics were proven to have a significant effect (Blanke and Andersen, 1984; Woodward and Latorre, 1985; Hendricks, 1986). IMO's stepwise introduction of $\mathrm{NO}_{x}$ emission limits led to research into the use of variable geometry turbines as in (Stefanopoulou and Smith, 2000). A more recent development and investigation of a large twostroke engine model without EGR was recently published in (Theotokatos, 2010; Baldi et al., 2015; Guan et al., 2014, 2015; Theotokatos and Tzelepis, 2015).

Only few publications have been made about the EGR control for large two-strokes. Hansen et al published two papers about modeling and control, respectively (Hansen et al., 2013b,a). The model was extended and improved by Alegret et al in (Alegret et al., 2015) by introducing the Cylinder By-pass Valve (CBV), changing the parameter estimation scheme and the development of a new exhaust temperature calculation. The authors of the present paper made a number of further extensions to the same model in (Nielsen et al., 2017b), where a simpler control-oriented model (COM) of the scavenge oxygen fraction was derived as well. A similar COM had earlier been presented in (Nielsen et al., 2015) along with a nonlinear controller. A joint state and parameter observer for the COM was presented in (Nielsen et al., 2017a).

A much larger amount of publications are available on the EGR control for automotive engines, typically including a VGT (van Nieuwstadt et al., 2000; Wahlström and Eriksson, 2011a,b; Wahlström et al., 2010; Wahlström and Eriksson, 2013; Wang et al., 2014; Huang et al., 2016). An investigation into the effect of fuel mix on the intake oxygen fraction on an automotive engine with EGR and observer design for this system was published in (Zhao and Wang, 2013, 2015). The design of EGR control for large two-stroke engines differ from the automotive engine especially in the differences between scavenging of 2-stroke and 4-stroke engines, lack of engine test bed availability (as explained in (Xiros, 2002)), system time constants, sensor availability and the general maturity of the field.

\subsection{Purpose}

Existing EGR feedback control is able to control $O_{s r}$ during steady operating conditions but suffers during loading transients. In (Hansen et al., 2013a) it was shown that the achievable performance with SISO feedback control is limited. A nonlinear controller with direct use of fuel flow and turbocharger speed signals where suggested in (Nielsen et al., 2015) but without thorough validation. The present paper extends the results from (Nielsen et al., 2015) significantly. The main contributions of the present paper are

1. The controller concept introduced in (Nielsen et al., 2015) is generalized to a class of first order Hammerstein systems that now include sensor delay.

2. Exponentially converging bounds of the control error are proven.

3. The controller is validated by closed loop simulation with an MVEM model, in an engine test bed and on a vessel operating at sea. 


\subsection{Outline of this paper}

Section 2 provides a brief summary of the two EGR models used. Section 3 presents the new controller concept as generalized to a class of first order Hammerstein models and proves minimum convergence bounds of the control error. The control concept is applied to the control-oriented EGR model in Section 4. Section 5 shows the results of closed loop simulation and presents experimental validation both on an engine test bed and on a vessel operating at sea.

\section{EGR System Models}

The controller presented in this paper is designed by the use of mathematical models of the EGR system behavior. A high-fidelity mean-value engine model (MVEM) is used for validation of closed loop properties. Controller synthesis by linearizing a similar MVEM was investigated in (Hansen et al., 2013a) where it was shown difficult to achieve both performance and robustness. The MVEM model also served as a basis of a simpler control-oriented model in (Nielsen et al., 2017b). In the present paper we design a nonlinear controller based on the COM similar to the controller presented in (Nielsen et al., 2015). The MVEM and the COM are summarized below.

\subsection{Mean-Value Engine Model}

The size and complexity of a two-stroke cross-head marine diesel engine makes practical experiments an expensive and thus scarce resource. Therefore it is highly advantageous to be able to simulate engine behavior when designing controllers. A model of the main gas flows and gas composition of the 4T50ME-X engine located in MDT's Diesel Research Center in Copenhagen was presented in (Hansen et al., 2013b). It had the form of a mean value, filling and emptying model, where many parameters were estimated from experiment data. This model was improved and extended in (Alegret et al., 2015), where the cylinder bypass valve was added and the parameter estimation scheme was changed. A few further changes were made in (Nielsen et al., 2017b), most notable the change from mass to molar flows and gas composition in order to better relate to the scavenge oxygen sensor. The latter model is used in the present paper for closed loop validation of the EGR controller.

The components represented in the MVEM are shown in Figure 1. Four volumes (red) are characterized by an isothermal pressure state $p_{i}$ in each

$$
\dot{p}_{i}=\frac{R T_{i}}{V_{i}}\left(\dot{n}_{\text {in }}-\dot{n}_{\text {out }}\right),
$$

where $R$ is the universal gas constant, $T_{i}$ is the temperature in the receiver, $V_{i}$ is the receiver volume and $\dot{n}$ represents total molar flows in and out of the receiver. The turbocharger speed, $\omega_{t c}$, is also modeled as a state

$$
\dot{\omega}_{t c}=\frac{P_{t u r b}-P_{c o m p}}{J_{t c} \omega_{t c}},
$$

where $P_{\text {turb }}$ and $P_{\text {comp }}$ are turbine and compressor power, respectively, and $J_{t c}$ is the moment of inertia of the total rotor system. Molar fractions of $\mathrm{O}_{2}$ in the scavenge and exhaust receivers $\left(O_{i}\right)$ are modeled as states

$$
\dot{O}_{i}=\frac{R T_{i}}{p_{i} V_{i}} \sum_{\text {input }=j} \dot{n}_{j}\left(O_{j}-O_{i}\right),
$$

where $\dot{n}_{j}$ is an input flow with oxygen fraction $O_{j}$. Standard submodels of valves, blower, turbine, compressor and intercooler calculate the molar flows $\dot{n}_{i}$ between said volumes based on input and output pressures and in most cases some additional variable or input $\epsilon_{i}$ such as valve opening or turbocharger speed

$$
\dot{n}_{i}=f\left(p_{\text {in }}, p_{\text {out }}, \epsilon_{i}\right)
$$

Note that $\dot{n}_{i}$ represents a molar flow, not a state of the model. The flow through the cylinder submodel is calculated as the mean of the flow through one engine revolution. A lean combustion reaction of the form

$$
\mathrm{CH}_{y}+\left(1+\frac{y}{4}\right) \mathrm{O}_{2} \rightarrow \mathrm{CO}_{2}+\frac{y}{2} \mathrm{H}_{2} \mathrm{O}
$$

is assumed. The virtual fuel molecule $\mathrm{CH}_{y}$ is introduced to simplify the analysis. The fuel constant $y$ refers to the total ratio of hydrogen to carbon among the different species in the fuel. Based on (5) the molar fraction of $\mathrm{O}_{2}$ in the total flow exiting the cylinders is calculated as

$$
O_{c o}=\frac{\dot{n}_{c i} O_{s r}-\dot{n}_{f}\left(1+\frac{y}{4}\right)}{\dot{n}_{c i}+\frac{y}{4} \dot{n}_{f}},
$$

where $\dot{n}_{c i}$ is the total flow entering the cylinders, $\dot{n}_{f}$ is the molar flow of the virtual fuel molecule $\mathrm{CH}_{y}$ and $\mathrm{O}_{s r}$ is the $\mathrm{O}_{2}$ fraction in the scavenge receiver. Outflow temperature from the cylinders are calculated from a modified limited pressure diesel cycle. A detailed explanation is found in (Alegret et al., 2015). Inputs to the MVEM model are fuel index, engine speed, $\mathrm{COV}$ and $\mathrm{CBV}$ valve openings and EGR blower speed.

The MVEM model is parameterized to represent the upper half of the engine load region (50-100\% load). The system is as such not different in the lower half of the load region, but the compressor, turbine and EGR blower maps do not include this region. Also, when operating in the lower load region the CBV valve is shut and auxiliary blowers (not modeled) aid the compressor in maintaining sufficient scavenge pressure.

\subsection{Control-Oriented Scavenge Oxygen Model}

Where the MVEM is intended to provide a highly accurate description of process physics the control-oriented model only aims at capturing the main dynamics and nonlinearity of the scavenge oxygen fraction. The simplicity and low number of parameters allow the use of the COM directly in the controller. 
The COM was first briefly presented in (Nielsen et al., 2015). In (Nielsen et al., 2017b) it was shown how to derive the COM from the MVEM. The MVEM can be considered as a cascade of two isolated systems: one of pressures/TC-speed and one of $\mathrm{O}_{2}$ fractions. Reduction of the $\mathrm{O}_{2}$ fraction system results in a first order Hammerstein model with 3 flows from the pressure/TC-speed system as inputs

$$
\tau \dot{O}_{s r}=-O_{s r}+O_{a}-\frac{\left(1+\frac{y}{4}\left(O_{a}+1\right)\right) \dot{n}_{f} \dot{n}_{e g r}}{\left(\dot{n}_{i c}+\frac{y}{4} \dot{n}_{f}\right)\left(\dot{n}_{i c}+\dot{n}_{e g r}\right)}
$$

Equation 7 is the control-oriented model. It includes ambient oxygen fraction $O_{a}$, a fuel dependent constant $y$ and a time constant $\tau \approx 12 \mathrm{~s}$ as parameters. Molar fuel flow $\dot{n}_{f}$, EGR flow $\dot{n}_{e g r}$ and intercooler flow $\dot{n}_{i c}$ are inputs to the model. In order to include the dynamics of the scavenge oxygen sensor a time delay of about 10-20 seconds can be added and the time constant can be increased to 15-20 seconds.

In (Nielsen et al., 2017b) it was shown how to estimate the three molar flows from signals that are commonly available to the EGR controller. The fuel flow is a control input from the governor and can be calculated as proportional to the product of engine speed $\omega_{c}$ and fuel index $Y$ as

$$
\dot{n}_{f}=k_{f} \omega_{c} Y
$$

where $k_{f}$ is the constant of proportionality. EGR flow is estimated by use of an EGR blower map, along with upand downstream pressures and blower speed. Intercooler flow is estimated as proportional to a polynomial expression $\beta$ in turbocharger speed $\omega_{t c}$

$$
\dot{n}_{i c}=\theta \cdot \beta\left(\omega_{t c}\right),
$$

where

$$
\beta\left(\omega_{t c}\right)=(1-\phi) \frac{\omega_{t c}}{1000 \mathrm{rad} / \mathrm{s}}+\phi\left(\frac{\omega_{t c}}{1000 \mathrm{rad} / \mathrm{s}}\right)^{2}
$$

and $\phi$ and $\theta$ are model parameters. This approximation is based on the assumption that the compressor operates close to a single line on a compressor map with almost constant efficiency. This is not an exact model and in Section 3 the model uncertainty is represented by treating $\theta$ as a bounded time-varying parameter.

Simulations show that (9) (with a fixed $\theta$ ) is fairly accurate in the upper half of the load range when the $\mathrm{CBV}$ opening is kept constant (Figure 3). However, the parameter $\theta$ is not easily obtainable from a priori engine data. Figure 4 shows an overview of how the flow estimators provide input to the COM. When compared to data from the engine test bed the COM is able to model the scavenge oxygen dynamics well, even in the lower half of the load range and during large load transients as shown in Figure 5 .

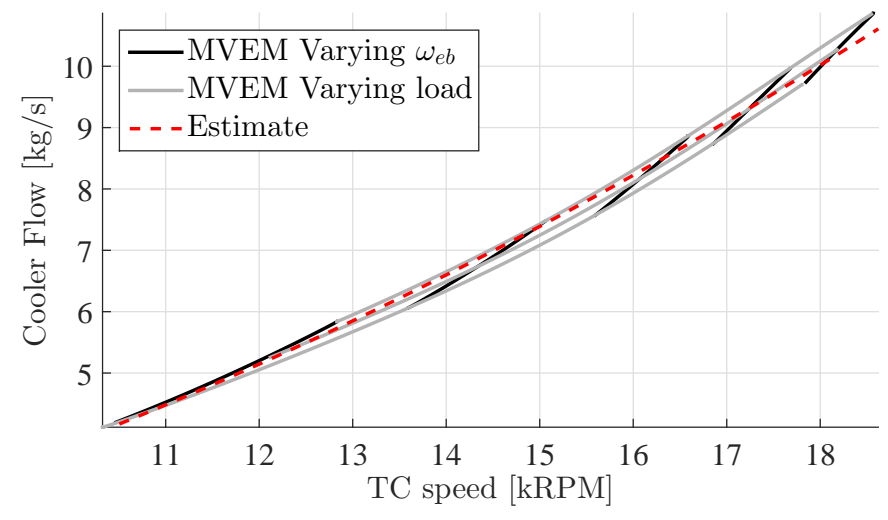

Figure 3: Simulation and estimation of cooler flow $\dot{n}_{i c}$ with constant CBV opening and varying engine load (43-100\%) and EGR blower speed.

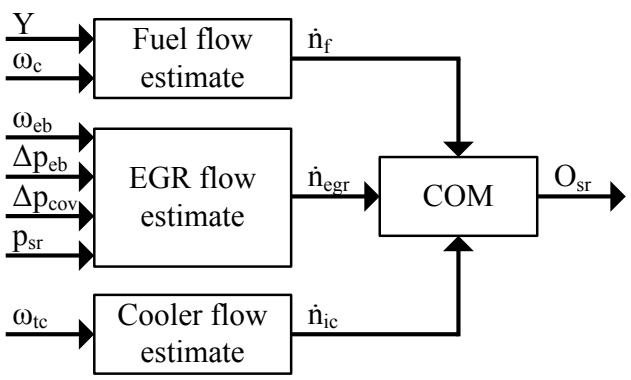

Figure 4: Overview of the control-oriented model with its input estimates and the signals used.

\section{Adaptive Feedforward Controller}

This section presents the concept of adaptive feedforward (AFF) control that we later apply to the EGR system. The controller presented here is fit for controlling a certain class of first order Hammerstein systems. An overview of the adaptive feedforward concept is shown in Figure 6. It consists of an estimator for a time-varying, and bounded, parameter $\theta(t)$ and an inversion of the input nonlinearity. The AFF controller takes advantage of known disturbances in order to compensate for them. The delayed measurement is used for fine-tuning of the inverted model, in order to ensure convergence of the control error.

Model inversion was used for air flow control of automotive engines in (Alfieri et al., 2009; Rupp and Guzzella, 2010; Qiu et al., 2016) in the form of Internal Model Control (IMC). Inversion of the plant model facilitates fast response to fueling transients, but control performance is highly dependent on the correctness of the model and its inverse. The additional feedback part of IMC is avoided with the adaptation element in AFF.

\subsection{Control Object}

The adaptive feedforward controller presented here is fit for a control object that can be modeled as a first order 

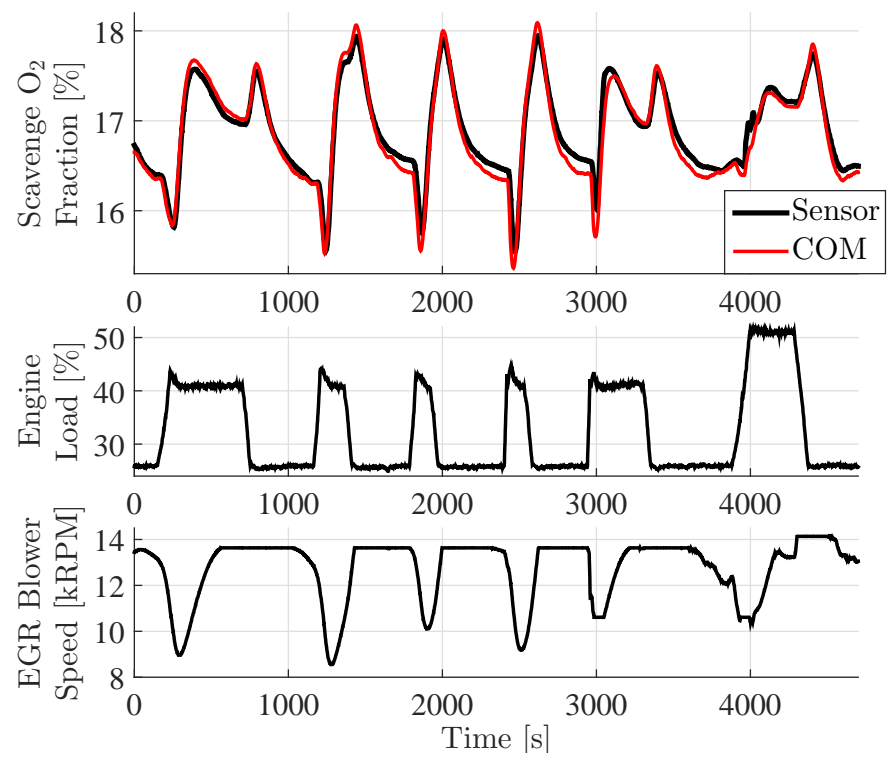

Figure 5: Comparison of $O_{s r}$ measured on test engine and estimated by COM during a series of engine RPM setpoint changes.

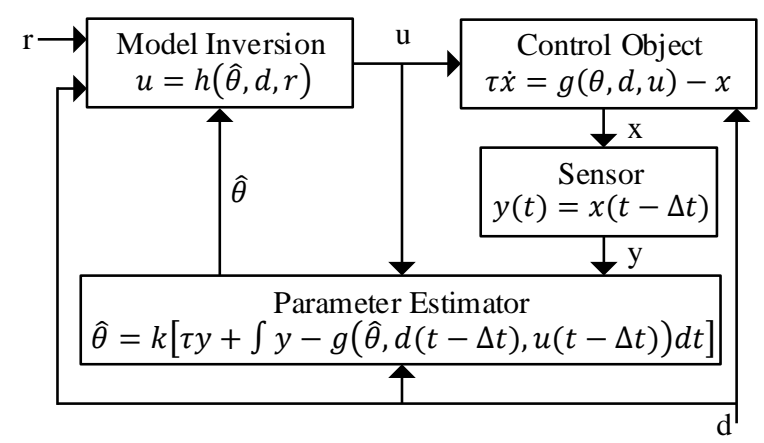

Figure 6: Structure of the adaptive feedforward controller. The parameter estimator fine-tunes the inverted model by use of the measurement.

Hammerstein system with a known time constant $\tau$ and one time-varying and bounded parameter $\theta(t)$ in the input nonlinearity. A vector of known disturbances $d(t)$ can be included as well and the controller is specifically efficient in compensating for these due to the feedforward principle. The differential equation that describes the system dynamics is

$$
\begin{gathered}
\tau \dot{x}(t)=g(\theta(t), d(t), u(t))-x(t) \\
y(t)=x(t-\Delta t) \\
\bar{\theta}-\kappa \leq \theta(t) \leq \bar{\theta}+\kappa
\end{gathered}
$$

where $u(t)$ is the controlled input and $g()$ is the input nonlinearity of the model. The state $x$ is measured as $y$ with delay $\Delta t$. The constants $\bar{\theta}$ and $\kappa$ describe the middle and half the width, respectively of the bounds of the timevarying parameter $\theta(t)$. The input nonlinearity $g()$ must be invertible in the actuated input $u$. This inverse function is defined as $h$ and we get

$$
r=g(\theta, d, h(\theta, d, r))
$$

where $r$ belongs to the set of valid setpoints for the controller. Our estimate of the parameter $\theta$ is designated $\hat{\theta}$ and we define parameter estimate error $\tilde{\theta}=\hat{\theta}-\theta$. For brevity we furthermore define the functions

$$
\begin{gathered}
\tilde{g}(\tilde{\theta}, d, u)=g(\theta+\tilde{\theta}, d, u)-g(\theta, d, u) \\
\tilde{g}_{h}(\tilde{\theta}, d, r)=g(\theta, d, h(\theta+\tilde{\theta}, d, r))-g(\theta, d, h(\theta, d, r))
\end{gathered}
$$

The input nonlinearity and its inverse must have bounded sensitivity to some of their parameters. The required bounds of the input nonlinearity are stated as

$$
\begin{aligned}
& \forall \theta_{1}, \theta_{2} \in D_{\theta}, t \in[0, \infty), \exists \rho, \exists \gamma>0: \\
& \gamma \tilde{\theta}^{2} \leq \tilde{g}(\tilde{\theta}, d(t), u(t)) \tilde{\theta} \leq \rho \tilde{\theta}^{2}
\end{aligned}
$$

If $g(\theta, d(t), u(t))$ is continuously differential w.r.t. $\theta$, the bounds in (15) can be expressed as

$$
\gamma \leq \frac{\partial g(\theta, d, u)}{\partial \theta} \leq \rho
$$

A bound must also be guaranteed for the sensitivity of the inverse of the input nonlinearity

$$
\begin{aligned}
& \forall \theta_{1}, \theta_{2} \in D_{\theta}, t \in[0, \infty), \exists \mu: \\
& \qquad\left|\tilde{g}_{h}(\tilde{\theta}, d(t), r)\right| \leq \mu|\tilde{\theta}|
\end{aligned}
$$

If $g(\theta, d(t), h(\hat{\theta}, d(t), r))$ is continuously differentiable w.r.t. $\hat{\theta}$ the bound in (17) can be expressed as

$$
\left|\frac{\partial g(\theta, d, h(\hat{\theta}, d, r))}{\partial \hat{\theta}}\right| \leq \mu
$$

If such bounds are guaranteed a controller based on a parameter estimator and inversion of the input nonlinearity can be proven to make the controller error converge at least exponentially to an interval around zero. This is shown in the following sections.

\subsection{Parameter Estimator}

The nonlinear parameter estimator from (Nielsen et al., 2017a) is used for estimating $\theta$

$$
\hat{\theta}=k\left(\tau y(t)+\int y(t)-g(\hat{\theta}(t), d(t-\Delta t), u(t-\Delta t)) \mathrm{dt}\right)
$$

where $k>0$. Note the direct gain from measurement $y$ to estimated parameter $\hat{\theta}$. The estimator described by (19) includes an implicit state due to the integral. In (Nielsen et al., 2017a) the parameter estimate bounds were proven to be

$$
|\hat{\theta}(t)-\bar{\theta}| \leq \kappa+(|\hat{\theta}(0)-\bar{\theta}|-\kappa) e^{-k \gamma t}
$$

where $\theta(t) \in[\bar{\theta}-\kappa ; \bar{\theta}+\kappa]$ and $\kappa \geq 0$. 


\subsection{Feedforward}

The feedforward part of the controller comprise on inversion of the input nonlinearity using the estimated parameter

$$
u=h(\hat{\theta}(t), d(t), r)
$$

where $\hat{\theta}(t)$ is the parameter estimate from $(19), d(t)$ is measured and $r$ is the reference. The controller structure was drawn in Figure 6.

\subsubsection{Proof of control error convergence}

Define the control error as $\tilde{x}=x-r$, then its time derivative is found with Equation 11a

$$
\tau \dot{\tilde{x}}=\tau \dot{x}=g(\theta, d, h(\hat{\theta}, d, r))-x
$$

Using (12) and (14) we get

$$
\begin{gathered}
\tau \dot{\tilde{x}}=\tilde{g}_{h}(\tilde{\theta}, d, r)+g(\theta, d, h(\theta, d, r))-x \Leftrightarrow \\
\tau \dot{\tilde{x}}=\tilde{g}_{h}(\tilde{\theta}, d, r)+r-x=\tilde{g}_{h}(\tilde{\theta}, d, r)-\tilde{x}
\end{gathered}
$$

From (17) we get

$$
-\mu|\hat{\theta}(t)-\theta| \leq \tilde{g}_{h}(\tilde{\theta}(t), d(t), r) \leq \mu|\hat{\theta}(t)-\theta|
$$

Furthermore, from Theorem 1,

$$
|\hat{\theta}(t)-\theta| \leq|\hat{\theta}(t)-\bar{\theta}|+\kappa \leq 2 \kappa+(|\hat{\theta}(0)-\bar{\theta}|-\kappa) e^{-k \gamma t}
$$

Combining (25) with (26) leads to two differential inequalities

$$
\begin{gathered}
\tilde{g}_{h}(\tilde{\theta}(t), d(t), r) \geq-\mu\left(2 \kappa+(|\hat{\theta}(0)-\bar{\theta}|-\kappa) e^{-k \gamma t}\right) \\
\tilde{g}_{h}(\tilde{\theta}(t), d(t), r) \leq \rho\left(2 \kappa+(|\hat{\theta}(0)-\bar{\theta}|-\kappa) e^{-k \gamma t}\right)
\end{gathered}
$$

Inserting these into (24)

$$
\begin{aligned}
& \tau \dot{\tilde{x}} \geq-\tilde{x}-\mu\left(2 \kappa+(|\hat{\theta}(0)-\bar{\theta}|-\kappa) e^{-k \gamma t}\right) \\
& \tau \dot{\tilde{x}} \leq-\tilde{x}+\mu\left(2 \kappa+(|\hat{\theta}(0)-\bar{\theta}|-\kappa) e^{-k \gamma t}\right)
\end{aligned}
$$

Using the Comparison Principle from (Khalil, 2002) allows us to solve the differential inequalities and get

$$
\begin{aligned}
& \tilde{x}(t) \geq-2 \mu \kappa+(\tilde{x}(0)+2 \mu \kappa) e^{-\frac{t}{\tau}}-\eta\left(e^{-k \gamma t}-e^{-\frac{t}{\tau}}\right) \\
& \tilde{x}(t) \leq 2 \mu \kappa+(\tilde{x}(0)-2 \mu \kappa) e^{-\frac{t}{\tau}}+\eta\left(e^{-k \gamma t}-e^{-\frac{t}{\tau}}\right)
\end{aligned}
$$

where

$$
\eta=\frac{\mu(|\hat{\theta}(0)-\bar{\theta}|-\kappa)}{1-k \gamma \tau}
$$

This result in (29) means that the absolute value of of the control error converges exponentially to $2 \mu \kappa$ or lower with a minimum convergence rate equal to the minimum of $\frac{1}{\tau}$ and $k \gamma$. The control error converges to zero when $\theta(t)$ is constant.

\section{AFF EGR Control}

This section shows how the adaptive feedforward controller concept is applied to the control-oriented model of the EGR system. The resulting AFF EGR controller has similarities to the nonlinear feedforward controller presented in (Alfieri et al., 2009), but the adaptation element of the AFF makes additional feedback control unnecessary.

\subsection{Definitions}

The AFF EGR controller consists of the parameter estimator (19) and the feedforward (21), with the following definitions

$$
x=O_{s r} \quad, \quad d=\left[\begin{array}{ll}
\dot{n}_{f} & \omega_{t c}
\end{array}\right]^{T} \quad, \quad u=\dot{n}_{e g r}
$$

Scavenge oxygen fraction is defined as the state. Fuel flow and turbocharger speed are defined as known disturbances. A flow controller enables us to treat EGR flow as the actuated input. The dynamics of this inner flow control loop is expected to be fast enough to not reduce performance of the outer oxygen control loop significantly. Simulations and experiments verify this assertion in later sections. The input nonlinearity $g()$ from $(7)$ is defined as

$$
g(\theta, d, u)=O_{a}-\frac{\left(1+\frac{y}{4}\left(O_{a}+1\right)\right) \dot{n}_{f} \dot{n}_{e g r}}{\left(\theta \beta\left(\omega_{t c}\right)+\frac{y}{4} \dot{n}_{f}\right)\left(\theta \beta\left(\omega_{t c}\right)+\dot{n}_{e g r}\right)}
$$

The small inaccuracy of (9) is compensated by continuously estimating $\theta$ as a time-varying parameter. The inversion of $g(\theta, d, u)$ with respect to $u$ is

$$
h(\theta, d, r)=\frac{\theta \beta\left(\omega_{t c}\right) \cdot\left(O_{a}-r\right)}{r-\frac{\theta \beta\left(\omega_{t c}\right) \cdot O_{a}-\dot{n}_{f} \cdot\left(1+\frac{y}{4}\right)}{\theta \beta\left(\omega_{t c}\right)+\frac{y}{4} \cdot \dot{n}_{f}}}
$$

with $r<O_{a}$. In special cases the right side of Equation (33) is outside the actuator limits or even undefined. This is handled as follows

$$
u=\left\{\begin{aligned}
h(\hat{\theta}, d, r) & \text { if } h(\hat{\theta}, d, r) \in\left[0 ; u_{\max }[\right. \\
u_{\max } & \text { otherwise }
\end{aligned}\right.
$$

Such special cases relate to the invertibility of $g()$ w.r.t. $\dot{n}_{\text {egr }}$. The issue is illustrated in Figure 7 . With $\dot{n}_{f}$ and $\theta \beta\left(\omega_{t c}\right)$ fixed, there are limits to how much $g()$ and thus $O_{s r}$ can vary when $\dot{n}_{e g r}$ is non-negative

$$
\begin{gathered}
g(\theta, d, 0)=O_{a} \\
\lim _{u \rightarrow \infty} g(\theta, d, u)=O_{a}-\frac{\left(1+\frac{y}{4}\left(O_{a}+1\right)\right) \dot{n}_{f}}{\theta \beta\left(\omega_{t c}\right)+\frac{y}{4} \dot{n}_{f}}
\end{gathered}
$$

A low EGR flow leads to a $g()$ close to $O_{a}$. Thus if $r$ is close to $O_{a}$ the result of the inversion in (33) is a low EGR flow setpoint $u$.

At the other end of the scale, a high EGR flow leads to a $g()$ close to the limit expressed by (36). If $r$ is close to this limit but above, the inversion $h()$ results in a high EGR flow. If $r$ is equal to the limit $h()$ is undefined and if 


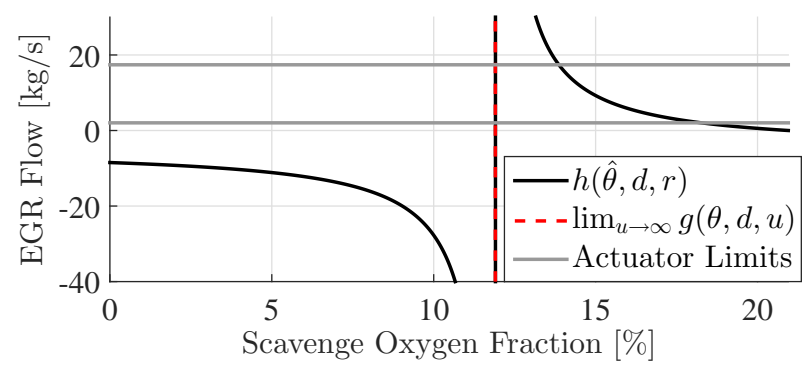

Figure 7: This figure illustrates the result of inverting the scavenge oxygen model without considering physical limits. Below a certain limit the inverted model dictates a negative EGR flow in order to decrease the oxygen level further. This issue is handled by the controller.

$r$ is below the limit, $h()$ is negative. For all three scenarios of a low $r$, the maximum EGR flow is the best option as it leads to the lowest $O_{s r}$. Note that even though the result of the inversion is beyond the actuator limits, the parameter estimator will converge as long as $\dot{n}_{e g r}>0$. The minimum EGR flow is positive as the EGR blower is not designed for running in zero or negative flow, but this is handled by the flow controller.

\subsection{Sensitivity Bounds}

The AFF controller presented in Section 3 requires the functions $g$ and $h$ to fulfill the sensitivity bounds specified in Section 3.1. With the definitions in (32) and (33), $g(\theta, d, u)$ and $g(\theta, d, h(\hat{\theta}, d, r))$ are continuously differentiable w.r.t. $\theta$ and $\hat{\theta}$, respectively. Therefore the bounds can be expressed by (16) and (18). Partial differentiation leads to

$\frac{\partial g(\theta, d, u)}{\partial \theta}=\left(1+\frac{y}{4}\left(O_{a}+1\right)\right) \frac{\dot{n}_{f} \dot{n}_{e g r} \beta\left(2 \beta+\frac{y}{4} \dot{n}_{f}+\dot{n}_{e g r}\right)}{\left(\theta \beta+\frac{y}{4} \dot{n}_{f}\right)^{2}\left(\theta \beta+\dot{n}_{e g r}\right)^{2}}$

and from the chain rule

$$
\frac{\partial g(\theta, d, h(\hat{\theta}, d, r))}{\partial \hat{\theta}}=\frac{\partial g(\theta, d, u)}{\partial u} \cdot \frac{\partial h(\hat{\theta}, d, r)}{\partial \hat{\theta}}
$$

where

$$
\frac{\partial g(\theta, d, u)}{\partial u}=\frac{\dot{n}_{f}\left(\frac{y}{4}\left(O_{a}+1\right)+1\right) \theta \beta}{\left(\beta \theta+\frac{y}{4} \dot{n}_{f}\right)(\beta \theta+h(\hat{\theta}, d, r))^{2}}
$$

and

$$
\begin{gathered}
\frac{\partial h(\hat{\theta}, d, r)}{\partial \hat{\theta}}=\frac{\left(r-O_{a}\right) \beta\left((r+1)\left(\frac{y}{4}\right)^{2}+\frac{y}{4}\right) \dot{n}_{f}^{2}}{\left(\left(1+(r+1) \frac{y}{4}\right) \dot{n}_{f}+\hat{\theta} \beta\left(r-O_{a}\right)\right)^{2}} \\
+\frac{\left(r-O_{a}\right)\left(2 \hat{\theta} \beta^{2}\left(1+(r+1) \frac{y}{4}\right) \dot{n}_{f}+\hat{\theta}^{2} \beta^{3}\left(r-O_{a}\right)\right)}{\left(\left(1+(r+1) \frac{y}{4}\right) \dot{n}_{f}+\hat{\theta} \beta\left(r-O_{a}\right)\right)^{2}}
\end{gathered}
$$

Unfortunately it is difficult to determine strict limits of $\gamma$, $\rho$ and $\mu$ due the complex couplings between the variables which appear in (37), (39) and (40). Conservative guesses can be achieved by defining independent intervals for $\dot{n}_{f}$, $\dot{n}_{e g r}, \beta, \theta$ and $\hat{\theta}$ and then evaluating the extremes of (37) and (38). For the engine test bed this results in limits of the order $\gamma=1.6 \cdot 10^{-5} \frac{\mathrm{s}}{\mathrm{mol}}, \rho=2.3 \cdot 10^{-3} \frac{\mathrm{s}}{\mathrm{mol}}$ and $\mu=7 \cdot 10^{-4} \frac{\mathrm{s}}{\mathrm{mol}}$.

This value of $\gamma$ results in a minimum convergence rate of about $1.6 \cdot 10^{-3} \frac{1}{\mathrm{~s}}$ if a typical observer gain of $k=100 \frac{\mathrm{mol}}{\mathrm{s}^{2}}$ is used. This corresponds to a time constant of about 10 minutes. Thus, even though exponential stability is guaranteed, the convergence is not guaranteed to be fast.

Further insight into the consequences of this issue can be gained by considering the scenarios in which the sensitivity of (37) is low. $\frac{\partial g}{\partial \theta}$ reaches its minimum when TC speed is high and fuel flow and EGR flow are low, simultaneously. This can only occur in a fast loading down scenario where the TC speed drops slower than the fuel flow due to the inertia of the rotor and the sensitivity will increase as fast as the TC speed drops. However, in a loading down scenario the response of the AFF controller is to increase the EGR flow, even if $\hat{\theta}$ has not fully converged. The end result is that even though the analytically derived minimum bound of the convergence rate is low, the expected convergence is better. This is also observed in the simulations and experiments in Section 5.

\section{Results}

The new EGR controller is now validated with an increasing level of realism. At first, closed loop simulation against the COM verifies the convergence properties. Then closed loop simulation against the MVEM to verify robustness toward the simplifications from MVEM to COM. Experimental validation is carried out first on an engine test bed connected to a water brake and finally on a vessel during operation at sea.

\subsection{Simulation}

The models and controllers are implemented and simulated in MATLAB Simulink. Dynamic simulation of pressure in the volumes that are small relative to the flow can be difficult for the solver, but Simulink's implicit ode15s solver is able to simulate the closed loop of the MVEM and AFF EGR controller at more than 80x real time on a standard PC.

\subsubsection{Simulation with COM}

In order to verify the convergence properties proven in Section 3 the closed loop setup shown in Figure 6 is simulated with $g$ and $h$ defined by (32) and (12), respectively, and the parameters shown in Table 1.

Results from such a simulation are shown in Figure 8. The convergence bounds are demonstrated with a step of the parameter $\theta$. Notice that the parameter estimate starts 
Table 1: Parameters for closed loop COM simulation

\begin{tabular}{lrl||lrl}
\hline$k$ & 100 & {$\left[\frac{\mathrm{mol}}{\mathrm{s}^{2}}\right]$} & $\theta$ & $120-125$ & {$\left[\frac{\mathrm{mol}}{\mathrm{s}}\right]$} \\
$\Delta t$ & 10 & {$[s]$} & $\hat{\theta}(0)$ & 120 & {$\left[\frac{\mathrm{mol}}{\mathrm{s}}\right]$} \\
$O_{a}$ & 20.95 & {$[\%]$} & $\phi$ & 0.54 & {$[-]$} \\
$y$ & 1.78 & {$[-]$} & $\tau$ & 10 & {$[s]$} \\
\hline
\end{tabular}

converging 10 seconds after the step due to the delay. The scavenge oxygen fraction reaches its setpoint again after about 50-100 seconds after the step. Thus the simulated performance is satisfying whereas the convergence bounds are quite conservative. The AFF controller has the property that if $\theta(t)$ is constant, then $\kappa=0$ and both parameter error and control error converges to zero. In Figure 8, $\theta$ is constant after 50 seconds and thus the errors converge to zero. These bound are illustrated in Figure 8 .

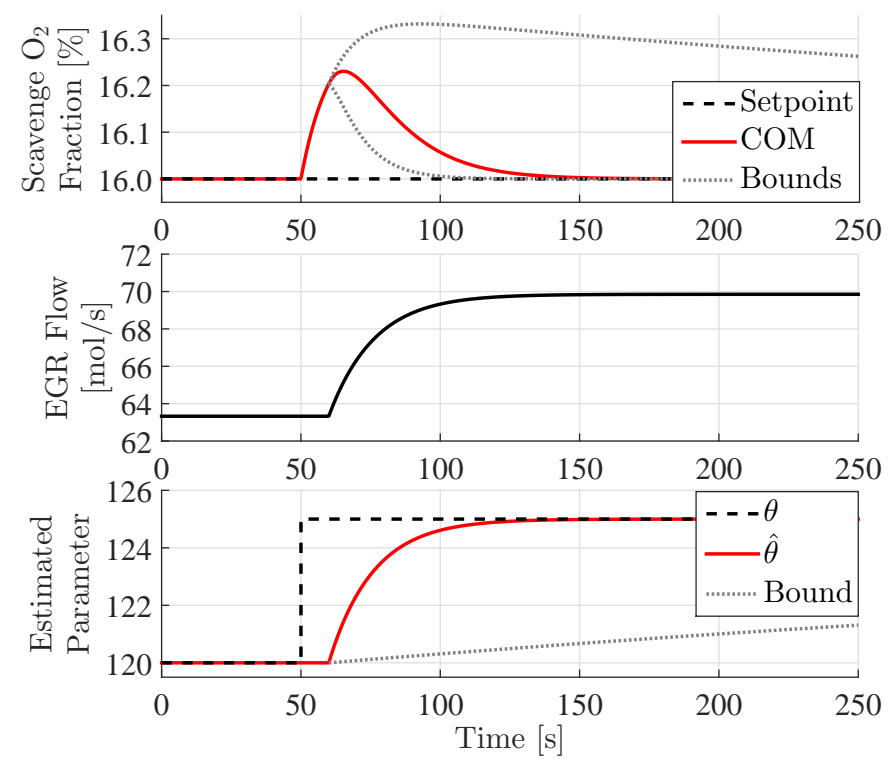

Figure 8: Closed loop simulation of the control oriented EGR model with AFF controller. The scenario is a step in the parameter $\theta$. The scavenge $\mathrm{O}_{2}$ fraction converges rapidly but the guaranteed bounds converge slowly.

\subsubsection{Simulation with MVEM}

Simulation with the COM is able to verify the convergence properties proven in the control concept, but simulation with the MVEM is needed to investigate whether the controller is robust toward the assumptions and simplifications made to reduce the MVEM to the COM. This includes the inner loop with EGR flow control, intercooler flow estimation, cylinder bypass valve and the more complex dynamics included in the MVEM. Furthermore, the MVEM is used for comparison to a PI controller (the reference EGR controller) and a feedforward controller (FF) identical to the AFF but without adaptation.

The first scenario is load steps with fixed CBV. Engine load is changed in steps as 43-69-100-69-43\%. Figure 9 shows the results. The AFF controller outperforms the PI and FF controllers significantly. The FF is able to avoid the error spikes seen with the PI, but the FF does not converge in steady state. In the second and third step (highest load) the AFF controller overcompensates due to the simplification of the intercooler flow estimate. The simulated $\theta$ changes abruptly at each step and then converges to a steady value. The estimate $\hat{\theta}$ converges to the new steady $\theta$ value as after every step.
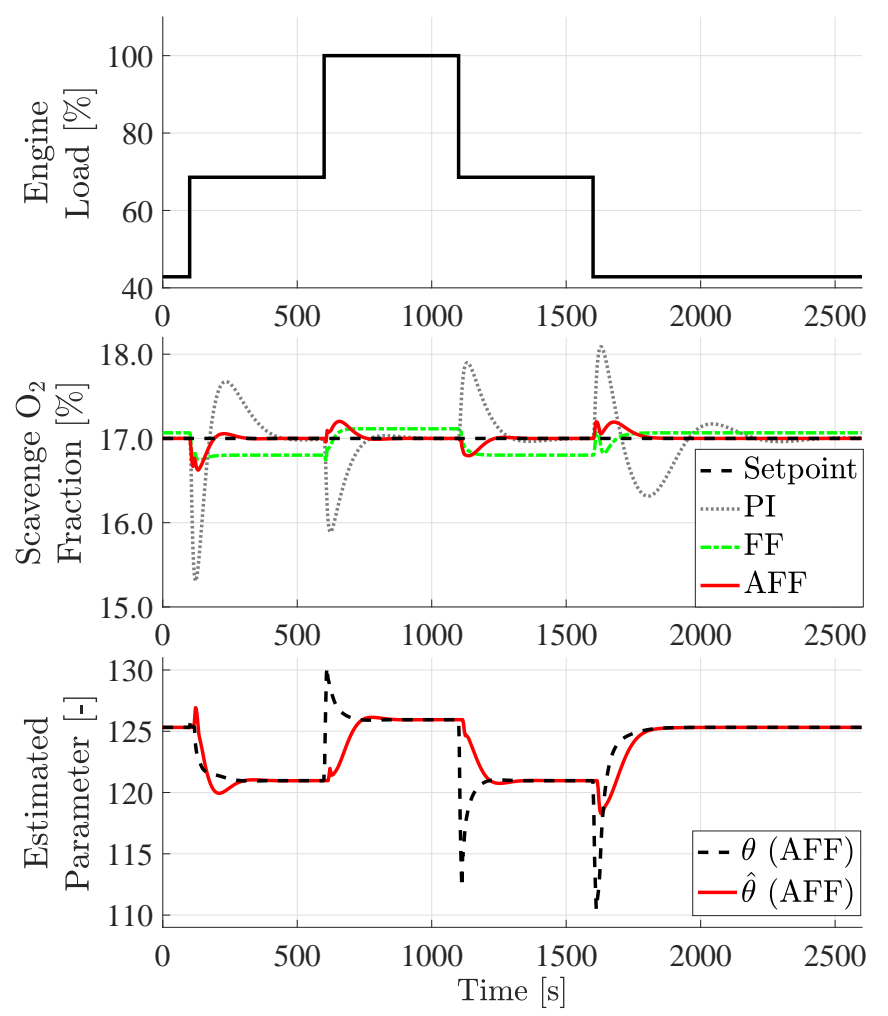

Figure 9: Comparison of engine load steps with respectively PI, FF and AFF controller, simulated with the MVEM. Both of the feedforward controllers avoid the large error spikes. The adaptation of the AFF makes the error converge to zero at steady state.

The second scenario is CBV opening steps at $69 \%$ engine load. Changes in the CBV opening is not included in the cooler flow estimation and is therefore not compensated directly by the feedforward part of the FF and AFF. Instead the parameter estimator has to adapt $\hat{\theta}$ in order to compensate for the steps. The initial responses of the three controllers are similar. The FF is unable to compensate for the disturbance due to its lack of adaptation. The AFF controller converges faster to the setpoint than the PI. The simulated $\theta$ now changes even more at each step than in the previous simulation. The estimate $\hat{\theta}$ still converges to the new steady $\theta$ value as after every step.

In all simulations $\theta(t)$ is practically constant between the steps. Thus the control error of the AFF converges to zero between the steps. The inability of the FF to convergence to the setpoint disqualifies it, and therefore it has not been part of the experiments. 

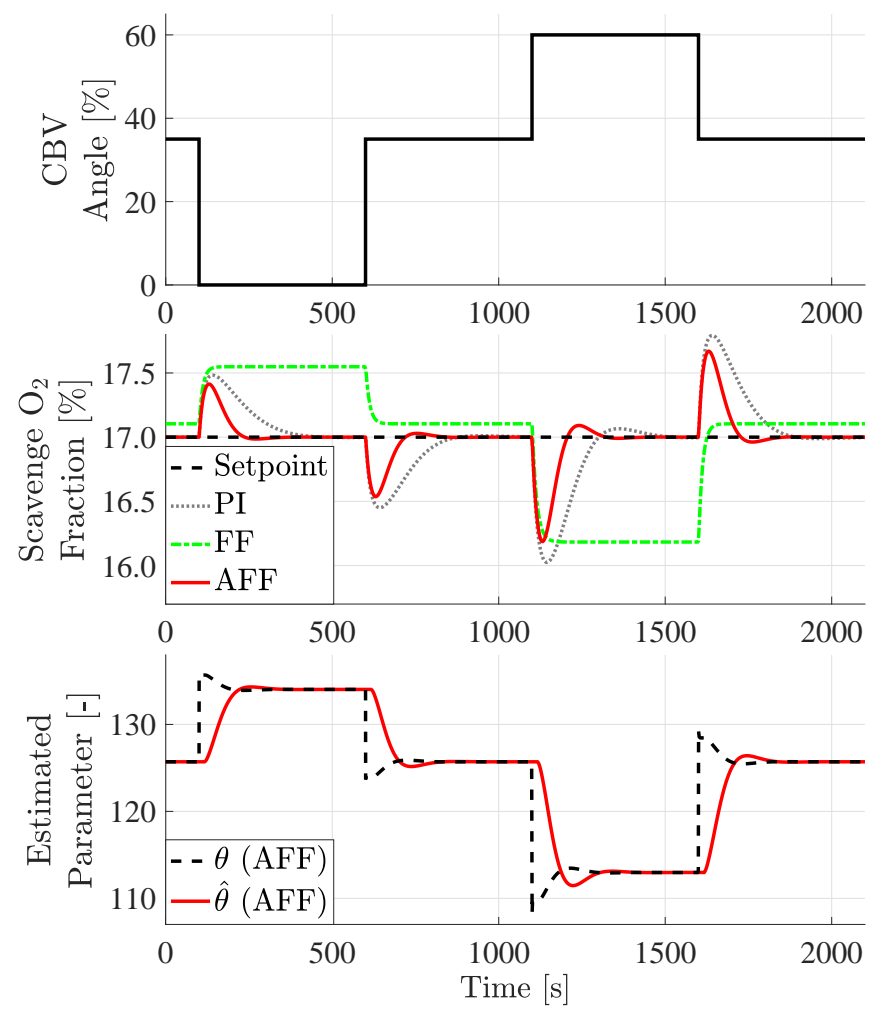

Figure 10: Comparison of CBV opening steps with PI, FF and AFF EGR controller, respectively, simulated with the MVEM. The nonadaptive feedforward ( $\mathrm{FF}$ ) is not able to compensate for the variation of CBV opening.

\subsection{Experimental validation}

The AFF EGR controller has been implemented as an option in a test version of the MDT EGR control software. This facilitates experimental validation of the design, first in an engine test bed and then on a vessel operating at sea.

\subsubsection{Experiments on Engine Test Bed}

The MVEM and the COM are based on the 4T50ME-X test engine located in the MDT Diesel Research Center in Copenhagen. The engine is fitted to a water brake where the engine load can be adjusted to fit the propeller curve.

In order to compare the AFF EGR controller to the reference PI controller, the two are subjected to similar engine load ramps from $26 \%$ to $42 \%$ in 80 seconds (Figure 11). The scavenge oxygen measurement clearly shows the difference in performance. With the PI controller $O_{s r}$ drops from $16.5 \%$ to below $15.9 \%$ whereas the nonlinear controller only lets $O_{s r}$ drop to $16.4 \%$. The test bed includes an opacity sensor in the chimney. The standard of the facility is that the opacity should remain below $12 \%$ and that opacity above $20 \%$ is critical. During test the normal level of opacity was $4 \%$. With the PI controller the opacity peaked at $16 \%$ during the transient, whereas the AFF peaked at only $8 \%$ opacity. These tests showed a great performance improvement from PI to AFF controller. As there are no measurements of the scavenge cooler flow it is not possible to calculate a reliable "true" $\theta$ value in this case. It is, however, observed that the estimate $\hat{\theta}$ changes somewhat after the step but otherwise remains within a small interval, as predicted by models and simulations.
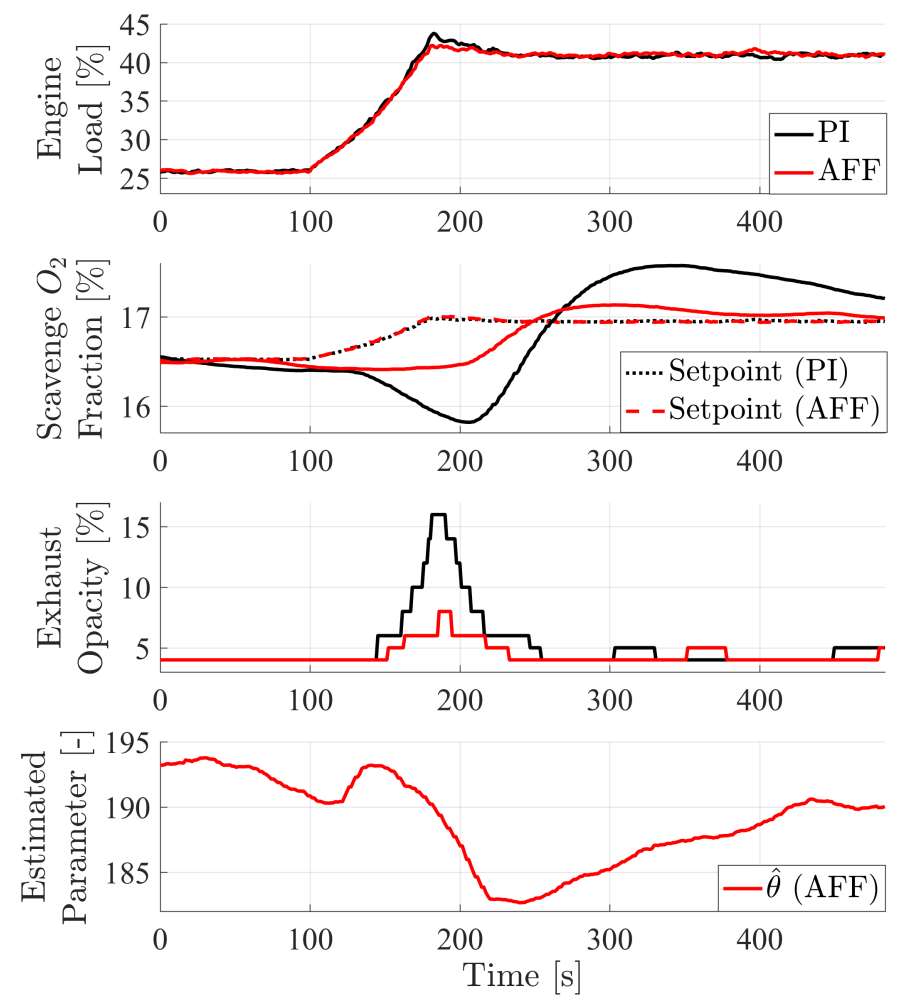

Figure 11: Comparison of similar engine load ramps with PI and AFF EGR controller, respectively, at engine test bed. A significant difference in scavenge oxygen fraction and exhaust opacity is observed, showing superior performance of the AFF over the reference controller.

\subsubsection{Experiments on Vessel}

To validate the AFF controller further it was tested on the container vessel Maersk Cardiff (with a 6S80ME-C9.2 engine) during operation at sea. A comparison between the two controllers where made, similar to the validation on the engine test bed. However, as the vessel engine drives a propeller rather than a water brake, the load transient scenario is an engine RPM setpoint step instead of a load ramp. The result is seen in Figure 12. The engine accelerates slightly faster with the AFF controller because the faster decrease of EGR flow results in a faster increase of scavenge pressure and thus a looser fuel index limiter. Another improvement is seen in the measurements of $O_{s r}$. With the PI controller it drops from $16.1 \%$ to below $13 \%$ during the transient. The AFF controller manages to keep $O_{s r}$ above $15.9 \%$. The difference is also seen in the opacity measurements which is fully saturated at $100 \%$ for 30 
seconds with the PI controller whereas it peaks at $91 \%$ with the AFF and then drops rapidly again. Note that conditions for opacity measurements on the vessel are not comparable to the conditions on the engine test bed, so the absolute values should not be directly compared. The parameter estimate $\hat{\theta}$ increases during the acceleration and then decreases to a steady value that is lower than before the step. These variations can be explained by the large decrease of EGR rate during acceleration and the auxiliary blowers which turn of at the final high load. As the actual flow through the scavenge cooler was not measured it is not possible to calculate a "true" $\theta$ for comparison.
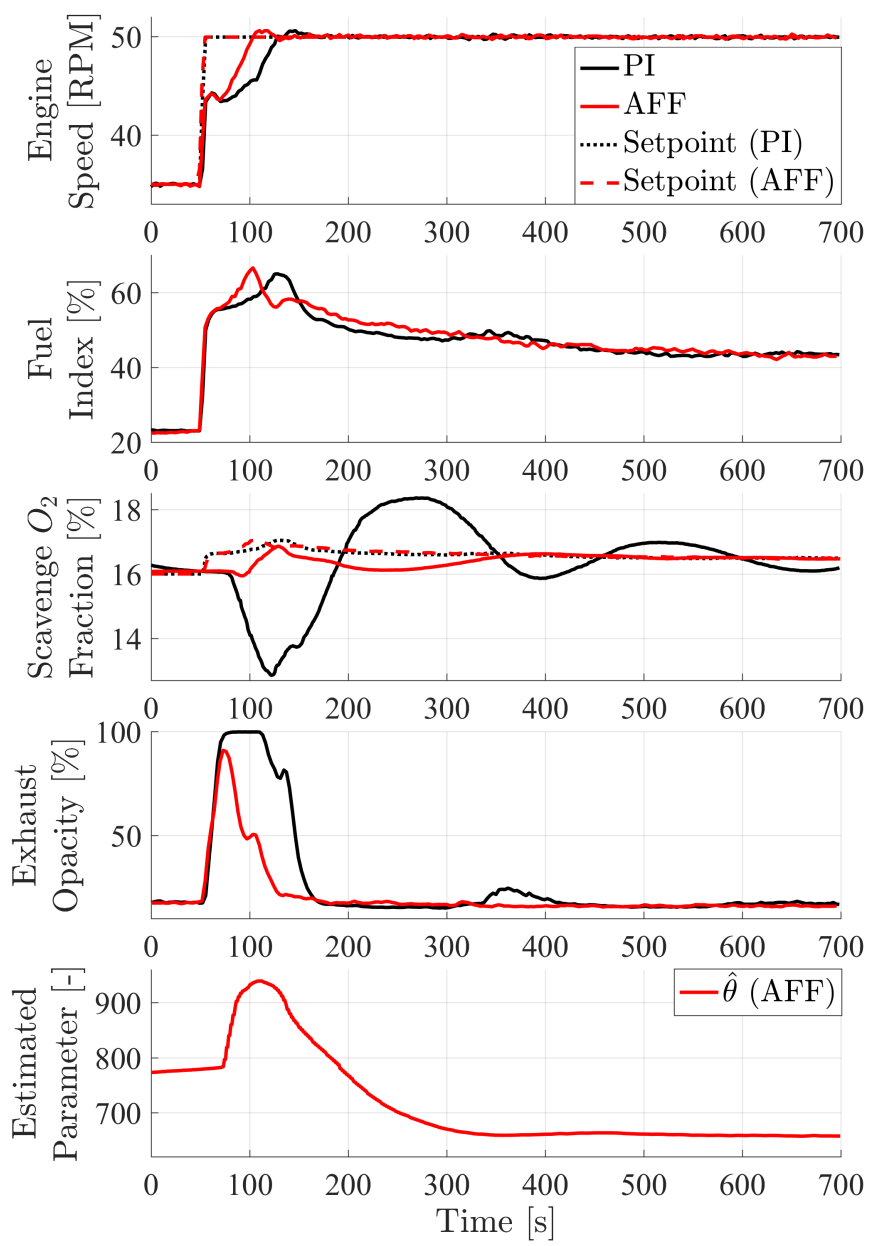

Figure 12: Comparison of similar engine RPM setpoint stepresponses with PI and AFF EGR controller, respectively, on the vessel Maersk Cardiff. A significant difference in scavenge oxygen fraction and exhaust opacity is observed, showing superior performance of the AFF over the reference controller.

The exhaust was filmed with a video camera during the transients. Figures 13 and 14 show stills from the videos. Thick black smoke was emitted for about 45 seconds in the PI case, whereas a much lighter smoke was emitted for about 20 seconds with the AFF.

Figure 15 shows a comparison of the steady state behavior of the controllers. The engine is running at $\sim 10.5 \%$

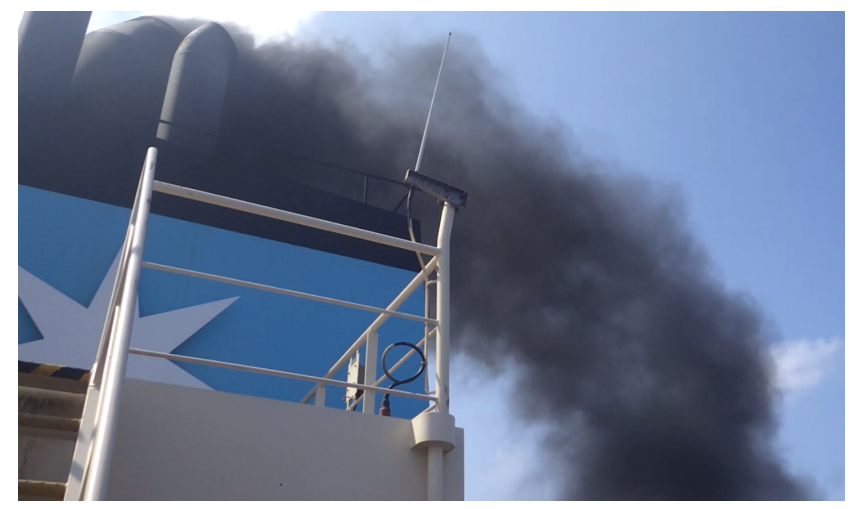

Figure 13: Exhaust smoke level with PI controller during engine speed step. Thick black smoke is emitted for 45 seconds.

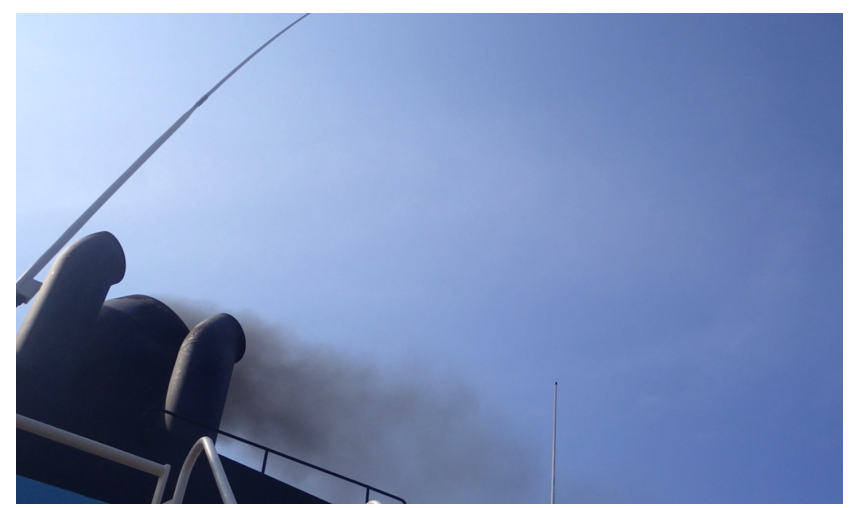

Figure 14: Exhaust smoke level with adaptive feedforward controller during engine speed step. Gray smoke is emitted for 20 seconds.

load. An oscillation of $0.3 \%$ load occurs with a period of 5 minutes. With the PI controller this load disturbance leads to an oscillation in $O_{s r}$ of $0.08 \%$. The AFF keeps it within $0.03 \%$ of the setpoint. If the EGR blower RPM is kept fixed $O_{s r}$ oscillates with amplitude 0.04\%. The AFF is seen to change the EGR blower speed faster than the PI in this scenario.

\section{Conclusions}

In this paper an adaptive feedforward controller design was generalized for a class of first order Hammerstein systems and exponential convergence bounds of the control error and a parameter estimate was analytically proven.

Furthermore the concept was applied to control the EGR system of a large two-stroke marine diesel engine. The AFF EGR controller was validated by closed loop simulation with an MVEM model and experiments on an engine test bed and on a vessel operating at sea. The validation showed the AFF controller to be a significant improvement compared to a PI controller in scenarios with large loading transients. Both opacity measurements and visual inspection showed a significant reduction of smoke formation during said transients. In a constant engine 


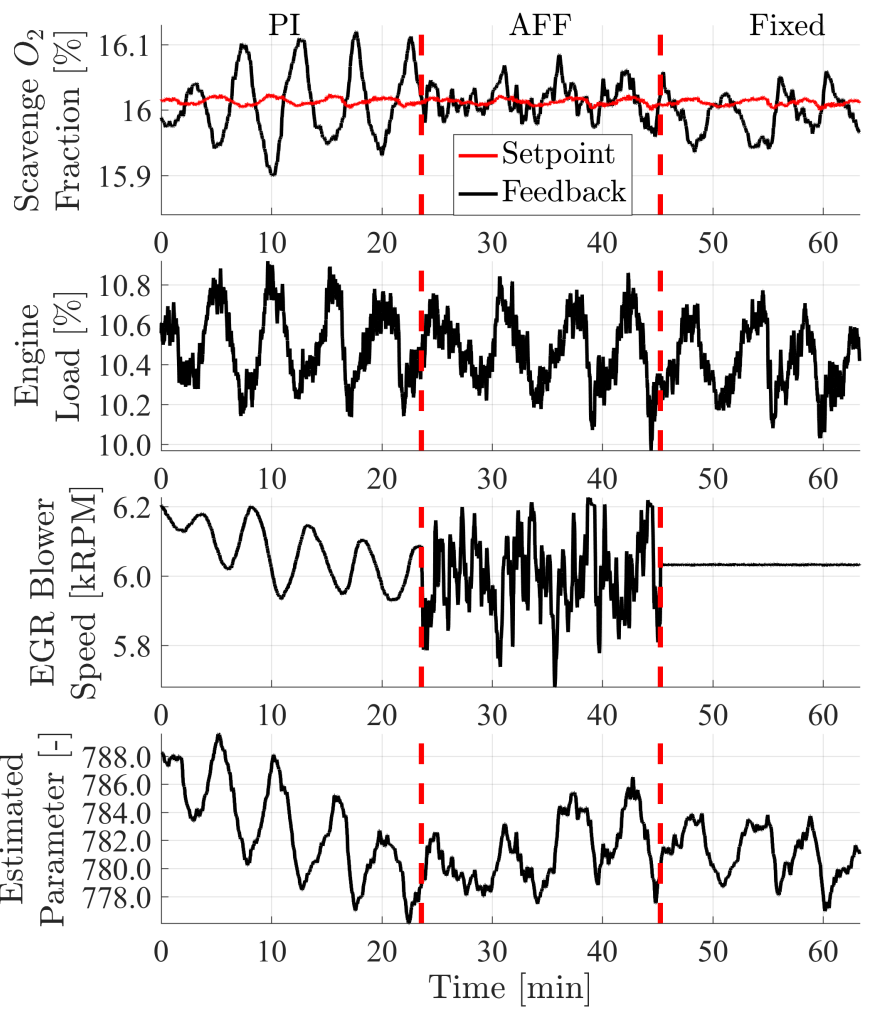

Figure 15: Comparison of existing PI controller, nonlinear controller and fixed EGR blower speed at close to steady state conditions. A small load oscillation is propagated to the scavenge oxygen level.

speed setpoint scenario the AFF controller also outperformed the PI, with better rejection of the disturbance from load oscillations.

The AFF controller concept enables use of the EGR system during maneuvering, without damaging the engine with soot formation and without violating legislation regarding visible smoke emission.

\section{Acknowledgment}

This work was partially funded by the Danish Agency for Science, Technology and Innovation, grant number 135500071B.

\section{References}

G. Alegret, X. Llamas, M. Vejlgaard-Laursen, and L. Eriksson. Modeling of a large marine two-stroke diesel engine with cylinder bypass valve and egr system. IFAC-PapersOnLine Elsevier Science, 48(16):273 - 278, 2015. ISSN 2405-8963. doi: 10.1016/j.ifacol.2015.10.292. 10th IFAC MCMC, 2015 Copenhagen.

E. Alfieri, A. Amstutz, and L. Guzzella. Gain-scheduled modelbased feedback control of the air/fuel ratio in diesel engines. Control Engineering Practice, 17(12):1417-1425, 2009. doi: 10.1016/j.conengprac.2008.12.008.

F. Baldi, K. Andersson, and G. Theotokatos. Development of a combined mean value-zero dimensional model and application for a large marine four-stroke diesel engine simulation. Applied
Energy, 154:402-415, 2015. ISSN 03062619, 18729118. doi: 10.1016/j.apenergy.2015.05.024.

R. Banning, M. A. Johnson, and M. J. Grimble. Advanced control design for marine diesel engine propulsion systems. Journal of Dynamic Systems Measurement and Control - Transactions of the Asme, 119(2):167-174, 1997. ISSN 15289028, 00220434.

M. Blanke. Requirements of adaptive techniques for enhanced control of large diesel engines. In Proc. IFAC Workshop on Adaptive Control and Signal Processing. Lund, Sweden. IFAC, 1986.

M. Blanke and J. A. Andersen. On modelling large two stroke diesel engines: New results from identification. In Proc. IFAC World Congress, pages 2015-2020, Budapest, 1984. Pergamon Press.

M. Blanke and P. B. Nielsen. The marine engine governor. In Proceedings Second International Conference on Maritime Communications and Control, pages 11-20, London, Nov. 1990. Society of Marine Engineers.

L. Eriksson and L. Nielsen. Modeling and control of engines and drivelines. Wiley, 2014. ISBN 1118479998, 9781118479995.

C. Guan, G. Theotokatos, and P. Zhou. Computational investigation of a large containership propulsion engine operation at slow steaming conditions. Applied Energy, 130:370-383, 2014.

C. Guan, G. Theotokatos, and H. Chen. Analysis of two stroke marine diesel engine operation including turbocharger cut-out by using a zero-dimensional model. Energies, 8(6):5738-5764, 2015. ISSN 19961073.

L. Guzzella and C. H. Onder. Introduction to modeling and control of internal combustion engine systems. Springer-Verlag, 2010. ISBN 3642107745, 3642107753, 9783642107740, 9783642107757.

J. M. Hansen, M. Blanke, H. H. Niemann, and M. Vejlgaard-Laursen. Exhaust gas recirculation control for large diesel engines - achievable performance with siso design. IFAC-PapersOnLine, Elsevier Science, 46(33):346-351, 2013a. doi: 10.3182/20130918-4JP-3022.00011. IFAC Proceedings Volumes.

J. M. Hansen, C. Zander, N. Pedersen, M. Blanke, and M. VejlgaardLaursen. Modelling for control of exhaust gas recirculation on large diesel engines. IFAC-PapersOnLine, Elsevier Science, 46 (33):380-385, 2013b. doi: 10.3182/20130918-4-JP-3022.00013. IFAC Proceedings Volumes.

HELCOM. Workshop in russia advances neca for ships in baltic and north seas. http://www.helcom.fi/news/Pages/Workshop-inRussia-advances-NECA-for-ships-in-Baltic-and-North-Seas.aspx, 2016.

E. Hendricks. Compact, comprehensive model of large turbocharged, two-stroke diesel engines. SAE Technical Paper Series, 1986. ISSN 01487191. doi: $10.4271 / 861190$.

J. B. Heywood. Internal combustion engine fundamentals. McGrawHill, 1988. ISBN 0071004998, 9780071004992.

M. Huang, K. Zaseck, K. Butts, and I. Kolmanovsky. Ratebased model predictive controller for diesel engine air path: Design and experimental evaluation. IEEE Transactions on Control Systems Technology, 2016. ISSN 10636536, 15580865. doi: 10.1109/TCST.2016.2529503.

International Maritime Organization. Marpol ANNEX VI and NTC 2008, 2013: With Guidelines for Implementation. 2013.

Hassan K. Khalil. Nonlinear systems. Prentice Hall, 2002.

K. V. Nielsen, M. Blanke, and M. Vejlgaard-Laursen. Nonlinear adaptive control of exhaust gas recirculation for large diesel engines. IFAC-PapersOnLine, Elsevier Science, 48(16):254 - 260, 2015. ISSN 2405-8963. doi: 10.1016/j.ifacol.2015.10.289. 10th IFAC Conf. on Manoeuvring and Control of Marine Craft, MCMC 2015 Copenhagen.

K.V. Nielsen, M. Blanke, and L. Eriksson. Adaptive observer for nonlinear parameterised hammerstein system with sensor delay a technology for ship emissions reduction. IEEE Transactions on Control Systems Technology, 2017a. In review.

K.V. Nielsen, M. Blanke, L. Eriksson, and M. Vejlgaard-Laursen. Control-oriented model of molar scavenge oxygen fraction for exhaust recirculation in large diesel engines. Journal of Dynamic Systems, Measurement and Control - ASME, 139, February 2017b. doi: 10.1115/1.4034750.

Z. Qiu, J. Sun, M. Jankovic, and M. Santillo. Nonlinear internal 
model controller design for wastegate control of a turbocharged gasoline engine. Control Engineering Practice, 46:105-114, 2016. doi: 10.1016/j.conengprac.2015.10.012.

D. Rupp and L. Guzzella. Adaptive internal model control with application to fueling control. Control Engineering Practice, 18 (8):873-881, 2010. doi: 10.1016/j.conengprac.2010.03.011.

A. Stefanopoulou and R. Smith. Maneuverability and smoke emission constraints in marine diesel propulsion. Control Engineering Practice, 8(9):1023-1031, 2000. ISSN 18736939, 09670661. doi: 10.1016/S0967-0661(00)00024-1.

G. Theotokatos. On the cycle mean value modelling of a large two-stroke marine diesel engine. Proceedings of the Institution of Mechanical Engineers Part M: Journal of Engineering for the Maritime Environment, 224(3):193-205, 2010. ISSN 14750902, 20413084.

G. Theotokatos and V. Tzelepis. A computational study on the performance and emission parameters mapping of a ship propulsion system. Proceedings of the Institution of Mechanical Engineers Part M: Journal of Engineering for the Maritime Environment, 229(1):58-76, 2015. ISSN 20413084, 14750902. doi: $10.1177 / 147509021$

M. J. van Nieuwstadt, I. V. Kolmanovsky, P. E. Moraal, A. Stefanopoulou, and M. Jankovic. Egr-vgt control schemes: Experimental comparison for a high-speed diesel engine. IEEE Control Systems Magazine, 20(3):63-79, 2000.

J. Wahlström and L. Eriksson. Modelling diesel engines with a variable-geometry turbocharger and exhaust gas recirculation by optimization of model parameters for capturing non-linear system dynamics. Proceedings of the Institution of Mechanical Engineers, Part D, Journal of Automobile Engineering, 225(7):960986, 2011a.

J. Wahlström and L. Eriksson. Nonlinear EGR and VGT control with integral action for diesel engines. Oil \& Gas Science and Technology - Rev. IFP, 66(4):573-586, 2011b

J. Wahlström and L. Eriksson. Output selection and its implications for mpc of egr and vgt in diesel engines. IEEE Transactions on Control Systems Technology, 21(3):932-940, 2013. ISSN 15580865, 10636536. doi: 10.1109/TCST.2012.2191289.

J. Wahlström, L. Eriksson, and L. Nielsen. Egr-vgt control and tuning for pumping work minimization and emission control. IEEE Transactions on Control Systems Technology, 18(4):993-1003, 2010. ISSN 15580865, 10636536. doi: 10.1109/TCST.2009.2031473.

H. Wang, Y. Tian, J. Bosche, and A. El Hajjaji. Modeling and dynamical feedback control of a vehicle diesel engine speed and air-path. Journal of Dynamic Systems Measurement and Controltransactions of the Asme, 136(6):061010, 2014. ISSN 15289028, 00220434. doi: 10.1115/1.4027502.

D. E. Winterbone and S. Jai-In. The application of modern control theory to a turbocharged diesel engine powerplant. Proceedings of the Institution of Mechanical Engineers, Part I: Journal of Systems and Control Engineering, 205(19):69-83, 1991. ISSN 20413041, 09596518.

J. B. Woodward and R. G. Latorre. Modeling of diesel engine transient behavior in marine propulsion analysis. Transactions - Society of Naval Architects and Marine Engineers, 92:33-49, 1985. ISSN 00811661.

N. Xiros. Robust Control of Diesel Ship Propulsion. Springer London, 2002. ISBN 9781852335434.

J. Zhao and J. Wang. Effect of exhaust gas recirculation on biodiesel blend level estimation in diesel engines. Journal of Dynamic Systems, Measurement and Control-transactions of the Asme, 135(1):011010, 2013. ISSN 00220434, 15289028. doi: $10.1115 / 1.4006884$

J. Zhao and J. Wang. Adaptive observer for joint estimation of oxygen fractions and blend level in biodiesel fueled engines. IEEE Transactions on Control Systems Technology, 23(1):80-90, 2015. ISSN 10636536, 15580865. doi: 10.1109/TCST.2014.2313003.

\section{Appendix A. Nomenclature}

A number of abbreviations, symbols and subscripts are used in this paper. These are indexed and briefly explained in the following three tables.

\section{Table A.2: Abbreviations}

\begin{tabular}{l|l}
$A F F$ & Adaptive feedforward \\
$C B V$ & Cylinder by-pass valve \\
$C O M$ & Control-oriented model \\
$C O V$ & Cut-out valve \\
$E G R$ & Exhaust gas recirculation \\
$I M C$ & Internal model control \\
$I M O$ & International maritime organization \\
$M D T$ & MAN Diesel \& Turbo \\
$M V E M$ & Mean-value engine model \\
$N E C A$ & NOx emission control area \\
$N O x$ & Nitrogen oxides \\
$P I$ & Proportional-integral \\
$R P M$ & Revolutions per minute \\
$S I S O$ & Single-input and single-output \\
$T C$ & Turbocharger
\end{tabular}

Table A.3: List of symbols

\begin{tabular}{|c|c|c|}
\hline$d$ & Known disturbances & {$[-]$} \\
\hline$g$ & Input nonlinearity & {$[-]$} \\
\hline$h$ & $\mathrm{~g}$ inverted w.r.t. $\mathrm{u}$ & {$\left[\frac{m o l}{s}\right]$} \\
\hline$J$ & Moment of intertia & {$\left[\mathrm{kg} \cdot \mathrm{m}^{2}\right.$} \\
\hline$k$ & Observer gain & {$\left[\frac{m o l}{s^{2}}\right.$} \\
\hline$\dot{n}$ & Molar flow & {$\left[\frac{\mathrm{mol}}{\mathrm{s}}\right.$} \\
\hline$O$ & Molar $\mathrm{O}_{2}$ fraction & {$[\%]$} \\
\hline$p$ & Pressure & {$[p a]$} \\
\hline$P$ & Power & {$[W]$} \\
\hline$r$ & Setpoint & {$[-]$} \\
\hline$R$ & Universal gas constant & $\left.\frac{\mathrm{J}}{\mathrm{Kmol}}\right]$ \\
\hline$T$ & Temperature & {$[K]$} \\
\hline$u$ & Actuated input & {$[-]$} \\
\hline$V$ & Volume & {$\left[m^{3}\right]$} \\
\hline$x$ & State variable & {$[-]$} \\
\hline$y$ & Ratio of $\mathrm{H}$ to $\mathrm{C}$ atoms in fuel & {$[-]$} \\
\hline$y(t)$ & Sensor output at time $t$ & {$[-]$} \\
\hline$Y$ & Fuel index & {$[\%]$} \\
\hline$\beta$ & Function of $\omega_{t c}$ & {$[-]$} \\
\hline$\gamma$ & Lower limit of sensitivity of $g(\theta)$ & {$\left[\frac{s}{m o l}\right.$} \\
\hline$\Delta t$ & Time delay & {$[s]$} \\
\hline$\theta(t)$ & Time-varying parameter & {$\left[\frac{\mathrm{mol}}{\mathrm{s}}\right]$} \\
\hline$\mu$ & Lower limit of sensitivity of $g(h(\hat{\theta}))$ & {$\left[\frac{s}{m o l}\right]$} \\
\hline$\rho$ & Upper limit of sensitivity of $g(\theta)$ & {$\left[\frac{\mathrm{s}}{m o l}\right]$} \\
\hline$\tau$ & Oxygen mixing time constant & {$[s]$} \\
\hline$\phi$ & Coefficient of $\beta$-function & {$[-]$} \\
\hline$\omega$ & Rotational speed & {$\left[\frac{\mathrm{rad}}{\mathrm{s}}\right]$} \\
\hline
\end{tabular}


Table A.4: Subscripts

\begin{tabular}{l|l||l|l}
$a$ & ambient air & $c$ & crankshaft \\
$c b v$ & cylinder bypass valve & $c i$ & cylinder in \\
$c o$ & cylinder out & comp & compressor \\
$c o v$ & cut-out valve & $e b$ & EGR blower \\
$e r$ & exhaust receiver & $f$ & fuel \\
$i c$ & intercooler & $\max$ & maximum \\
$s r$ & scavenge receiver & $t c$ & turbocharger \\
turb & turbine & &
\end{tabular}

